\title{
STUDY OF INSTITUTIONAL SOLAR PHOTOVOLTAIC SYSTEM AND ITS OPTIMIZATION IN DESIGN
}

\author{
Ramesh Ranabhat ${ }^{1}$, Sundar Bahadur Khadka ${ }^{2}$ \\ ${ }^{1}$ Mechannical Department, Institute of Engineering, Pulchowk Campus, T. U, Nepal \\ Email Address: ramesh.ranabhat@ioe.edu.np \\ ${ }^{2}$ Alternative Energy Promotion Center, Khumaltar, Nepal \\ Email Address: sundar.khadka@aepc.gov.np
}

\begin{abstract}
Energy is one of the important necessities of the society and basic for sustainable development. It is derived from the different fuel resources which are grouped into different categories based on the fuel characteristics, monetization, resources availability, dependency etc.Total annual energy consumption of our country Nepal is 401 Million GJ (WECS 2010). Till date, around $12 \%$ population has access to electricity through renewable energy sources. Around $23 \mathrm{MW}$ of electricity has been generated from micro hydro schemes, $12 \mathrm{MW}$ from solar PV system, less than $20 \mathrm{KW}$ from wind energy etc. In this context most of the rural area is not connected with the national Grid line and the rural area people are using the solar home system (SHS) for the lighting purpose where people can have lights for nearly 4 hours. However in Urban area people have alternative power backup. People in the urban area were used Inverter based power backup intensively and in the office Diesel Generator was used in most of the places during load-shedding period.Government of Nepal with the support from the Donor Agencies is providing subsidies to the SHS for rural household as well as the ISPS for the institutional purpose. Various companies install ISPS in the rural area annually but the most of the system is nonfunctional after a couple of years of installation.

This study is focused to perform a comprehensive study on determining the size of the various components used in institutional solar photo-voltaic system (ISPS), point out the system design error in the previously installed system and proposed a sustainable approach of designing ISPS.
\end{abstract}

Keywords: energy, solar-home system, sustainable development, institutional solar photo-voltaic system

\section{Introduction}

Energy is an important aspect of human life. In the past few centuries, energy consumption has increased dramatically to a point where humans are very much dependent of energy. Under the current nonrenewable extraction technique of burning fossil fuels there are many externalities that are negatively impacting the earth. Society is approaching a limit where these formerly cheap forms of energy will become more expansive due to the difficulty of their extraction. As such, it is apparent that new forms of energy will develop out of necessity to fulfill the energy demand. The purpose of this study is to examine the different aspects of the promising area of solar energy for effective system design.

Nepal has about 300 sunny days a year, and the average insulations lies between 4 to $5 \mathrm{Kwh} / \mathrm{m}^{2} /$ day (WECS 1996, MoEST 2003). Nepal's solar energy potential is estimated to be about 26 million MW (WECS, 1996).NTC (Nepal Tele Communication) has installed more than 6,000 units of 50W module solar PVs.NEA installed around 22,000 household of about 30 to $50 \mathrm{KW}$ capacities PVs at Simikot, Gamgadhi, Tatopani (MoEST) and the SHS consist of a 32 to $36 \mathrm{~W}$ solar Panel, lead acid battery and charge controller. Thus, individual solar photovoltaic system is well adapted to meet rural energy needs.Even though, Solar PV technology is now being practiced in every sector but the proper selection of the equipment and the proper design of PV technology have not done yet which leads to the failure of PV technology in most of the case. The failure of the technology due to poor design is 
less significant in small system but in case of large system it is significant that the design should be appropriate. The design of PV technology decides the cost of the system.

Moreover, there is no grid line in most of the rural area of Nepal. Micro hydro may be the alternative way to generate Electricity but due to the scatter population and the Geographic condition, micro hydro is also not feasible. Hence, Solar PV technology is only a sustainable and alternative renewable energy source of generation of Electric Energy at that place. It is now being practiced as an alternative energy source but due to improper selection of technology and the poor design, the PV system fails. The design of PV technology is different in different sector and it is site specific so design of PV system is very important to make the system sustainable and viable.

Installation of ISPS has grown smoothly after FY 2006/07 as the curve has smooth increasing trend after 2006/07 (See Figure 1). The installation of ISPS started in 1993/94. There after installation increased slowly until 1996/97. The installation of ISPS is high particularly in the years 2000/01 and 2005/06. So far 402 ISPS have been installed and total installed capacity is $217,789 \mathrm{KWp}$

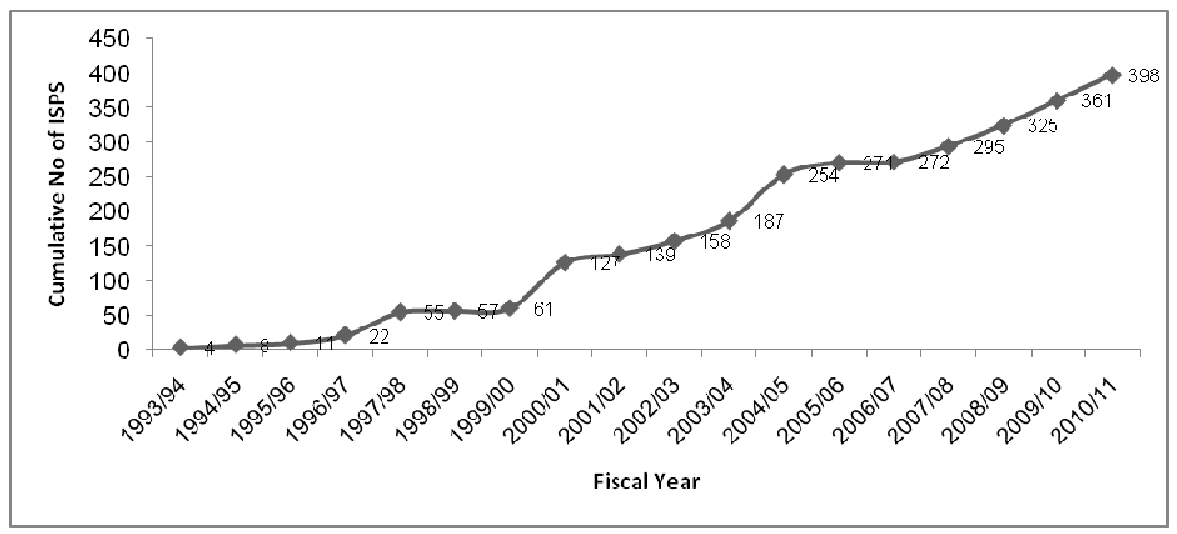

Fig1 Cumulative Number of Institutional Solar PV Systems by Year

(Source: status of solar photovoltaic sector in Nepal)

\section{Gap in the existing design practices}

Analysis of the existing design practices of the ISPS reveals following gap in the design of the ISPS.

a) Survey and the energy required calculation

In the existing practice, proper site survey is not conducted before installation of the ISPS. The load characteristics are not properly studied before the final design. The current consumed to run the equipment is not properly studied before the installation of the ISPS. Similarly, the electricity required per day is also not calculated properly.

b) Probable loss in the System

In the existing design practice, there is no any consideration of system losses. In fact, the system loss depends upon the components used and its efficiency but there is no any calculation for the system loss and the compensation of loss in the system.

c) Panel sizing

In the panel sizing the system loss is not included, hence the existing system undersize the panel.

d) Charge Controller sizing and selection

In most of the cases, the ordinary PWM charge controller is used, but by using the PWM charge controller there occur inherent system losses and that losses is not compensated in the design. Also, the charge controller is selected by the twice the value of the short circuit current or the load current but it is not necessary which causes the oversize of the charge controller. 
e) Battery sizing and selection

In the battery sizing, the loss in the inverter is not included in the existing design practice. Moreover, the effect of the inverter efficiency in the sizing of the battery is not considered. Battery is not selected on the basis of charging current and the discharging current. Some of the systems are still using C@20 battery in the system.

f) Cable sizing

Wire sizing depends upon the three factor, system Voltage, current passing through the cable and the distance between the Solar Array and the Charge Controller. As the distance increases, the wire size is also increases. The present design practice of wire sizing lacks in sizing the cable in term of the system voltage, current flowing in the cable and the distance between the Solar Array and the charge controller.

g) Inverter selection

Most of the cases, the local inverter is selected. The local inverter efficiency is nearly $70 \%$ hence the $30 \%$ loss is not compensated in the system design.

h) Grounding and the protection

In the present design there is no proper grounding in the system, earthing is done at the panel side only. Inverter of many ISPS is not working; this is because of the non properearthing in the inverter side. Moreover, the devices like the surge protector and the lightning protector is not used in the system.

i) Energy Guarantee

The present design practice is a watt based design; it is unable to guarantee the energy delivered by the system.

\section{Research methodology}

The ISPS system installed under AEPC subsidy programme are selected. The existing design parameters were taken for the study. The system designed was compared with the existing design in respective device.

\subsection{Survey}

First, step in doing design is the survey of the place and the technical parameters of the equipment for which power is given. Survey of the ISPS design includes the inspection of the instruments. All the technical data of the instruments is noted at this stage. How much AC current is consumed to run the equipment is also noted by the help of the Clamp Meter. The running current and the standby current is also noted. Equipment like printer has 3 modes: Starting, printing and the standby mode. Hence, the current consumption is also different in this different mode. This current is also noted at this stage. Operation hour for each equipment is also noted. Hence an Energy Requirements table is prepared at this stage. After the technical data is taken then the place where the Solar Panel is installed is also located with the help of Compass. The place should be free of shading from dawn to dusk. The Position of the control box and the Battery box is also located at this time. The actual energy requirement is calculated as follows.

For Printer and photocopier etc, three data has to be taken.
a. Starting Current
b. Printing Current
c. Standby Current 
Table 1 Energy Requirement calculations

\begin{tabular}{|c|c|c|c|c|c|c|}
\hline S.N & Description & Wattage(W) & Qty. & $\begin{array}{c}\text { Total } \\
\text { Wattage (W) }\end{array}$ & $\begin{array}{c}\text { Operating } \\
\text { hour( }(\mathrm{h})\end{array}$ & $\begin{array}{c}\text { Energy Required } \\
(\mathrm{Wh})\end{array}$ \\
\hline 1 & $\begin{array}{c}\text { LCD } \\
\text { Computer }\end{array}$ & 140 & 12 & 1680 & 8 & 13440 \\
\hline 2 & Scanner & 60 & 2 & 120 & 8 & 960 \\
\hline 3 & Printer & 580 & 1 & 580 & 8 & 4640 \\
\hline & $\begin{array}{c}\text { Total } \\
\text { Wattage }\end{array}$ & & & \multicolumn{3}{|c|}{ Total Energy Required } \\
\hline
\end{tabular}

The voltage of operation is $220 \mathrm{~V}$; hence total energy requirement for running printer is calculated by including the starting current, printing crrent and the standby current as well. Then only total energy requirement for running printer for specified period is obtained. Starting current is also called the surge current or the thermal current. Therefore, this peak current is also considered for the estimation of the inverter. Thus, accordingly all parameters were taken into account for the design.

\section{Results and Discussion}

\subsection{Existing Design of ISPS}

The sizing of Institutional System basically means estimating recommended daily load, battery size, controller ratings and wire sizing for given size of solar module or estimating the parameters of Solar Photovoltaic System (module capacity, battery size, controller rating and cable size) for the given load. Internationally accepted system sizing norms and standards are not available but each country has their own guidelines on system sizing. Nepal has developed its own Quality Standard (NEPQA), which also incorporates some guidelines on system sizing. Design of the Institutional Solar PV system begins after the collection of detail information about electricity consuming loads or devices and their operation from the consumer.

\subsection{Status of sampled ISPS supported by AEPC}

It is of big concern that the supported ISPS is now at working condition or not. So, to make a concrete data about the installed ISPS and help making policy for sustainability of the ISPS, monitoring of the ISPS is done. The status of sampled ISPS is tabulated as follows:

Table 2 Problem cases in the Sample ISPS

\begin{tabular}{|c|c|c|}
\hline S. N. & Problem & Cases \\
\hline 1. & $\begin{array}{c}\text { Inverter Not } \\
\text { Working }\end{array}$ & 8 \\
\hline 2. & $\begin{array}{c}\text { Battery Not } \\
\text { Working }\end{array}$ & 7 \\
\hline 3. & Low Power & 3 \\
\hline 4. & Charge Controller & 1 \\
\hline 5. & Inverter Burnt-out & 1 \\
\hline
\end{tabular}


The monitoring result of the sampled system found many problems in the field as depicted in the Table 2. To mitigate the problem find in the field and the gap in the existing design following design methodology of ISPS was proposed.

\subsection{Proposed design of ISPS}

To fill the gap in the existing design practice, a sustainable approach for designing the institutional photovoltaic system is proposed. Hence, the sustainable design procedures are as follows.

\subsubsection{Panel selection and design}

Panel is selected on the basis of the availability of the panel and installation cost. No matter whether use the low capacity panel or high capacity panel the output is almost the same. But, the installation cost for the low power panel is a bit high because it demands for high amount of structure and the cable. Material cost as well as man power for low power panel is obviously high. Hence, one should also consider for these factors while selecting the panel. Moreover, the technical parameter of the panel is more important while selecting the panel. The $\mathrm{I}_{\mathrm{mp}}$ and the $\mathrm{V}_{\mathrm{mp}}$ of the panel is key to the selection of the panel. Before the design of the system, we have to select the panel. The Solar Module or the Panel is of 12 Volt or 24 Volt type. If we use low power Panel then it is of 12 Volt type and if we choose high power panel then it is of 24 Volt type. Depending upon the system we may also select the panel.

\subsubsection{Insolation}

Insolation is the total energy received from the sun in a day in a unit surface area on the earth. The unit of insolation is watt-hour per sq.m. per day. For Nepal the yearly average insolation can be taken around 4500 to $5500 \mathrm{Wh} / \mathrm{m}^{2} /$ day. The exact value of solar insolation is determined with the help of Homer Software. To find out the solar isolation via Homer software, site latitude and longitude has to be fed in the software. The site latitude and longitude is easily found out by the google search through internet.The latitude and the longitudes of the particular place are determined from the google.

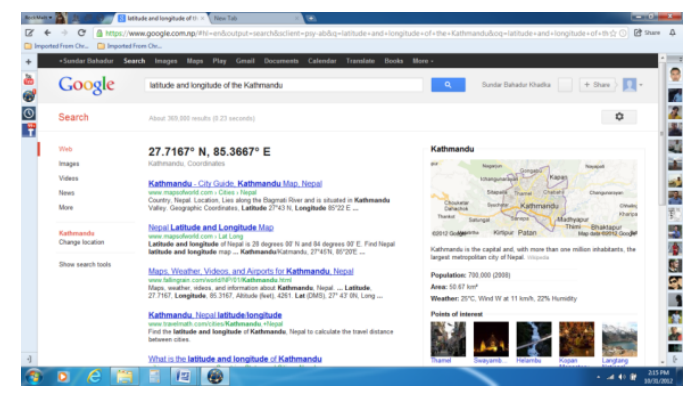

Fig 2 Determination of site longitude and latitude via google

From the Homer the insolation of the Kathmandu valley is found to be $4.97 \mathrm{Kw} / \mathrm{m}^{2} /$ day

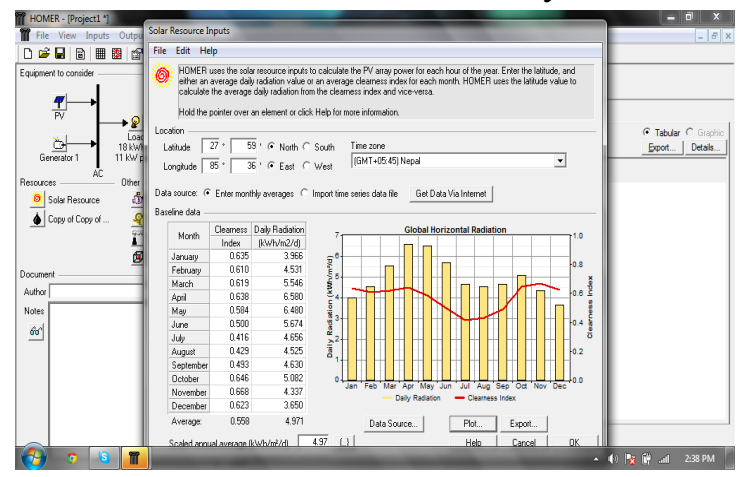

Fig 3 Determination of Insolation by Homer 


\subsubsection{Peak sun}

Peak sun is the number obtained by division of isolation by $1000 \mathrm{~W}$ per sq.m. per day.

Peak sun for Kathmandu valley $=\frac{\text { Insolation }}{1000}$ hour

$$
\begin{aligned}
& =\frac{4970}{1000} \text { hour } \\
& =4.97 \text { hour }
\end{aligned}
$$

\subsubsection{Loss factor}

Loss factor is an important parameter that must be compensated in the sustainable design of the ISPS. In Solar PV system following loss factor have to be included occurs.

The tolerance of the PV Module

Generally the module tolerance level is $5 \%$. So there is inherent loss of $5 \%$ due to panel tolerance.

$>\quad$ Efficiency of Charge Controller

The MPPT charge controller is $90 \%$ efficient so there is loss of $10 \%$ at the charge controller.

Battery Efficiency

Solar Batteries are $85 \%$ efficient so there is $15 \%$ loss in the Battery

$>\quad$ Inverter Efficiency

The Solar Inverter is $90 \%$ efficient so there is $10 \%$ loss in the System.

There is $3-5 \%$ loss in the cable also.

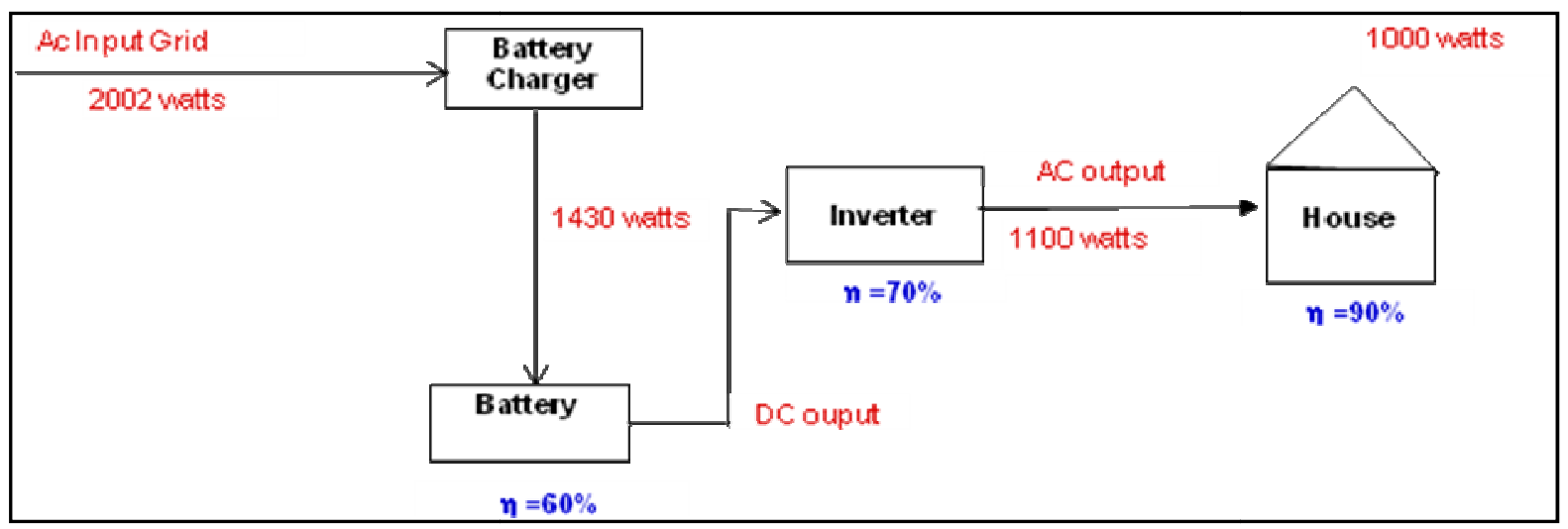

Fig 4 Efficiency of Different Units

Table 3 Loss in Terms of Money

\begin{tabular}{|l|c|}
\hline Cost of Charging per day (NRs.) & 64.06 \\
\hline Loss of Energy (8.008-4 Kwh per day) & 4.008 \\
\hline Cost of Lost Energy (NRs.) & 32.064 \\
\hline Loss in One Month (NRs.) & 961.92 \\
\hline Loss in One Year (NRs.) & 11543.04 \\
\hline Loss in 10 Years (NRs.) & 115430.4 \\
\hline
\end{tabular}




\subsubsection{System voltage}

Most of small ISPS is selected on 24 Volt systems and the large ISPS has to be designed on 48 Volt systems. Depending upon the size of the system and the component availability System Voltage is selected. System voltage is also based upon the battery bank. If the battery bank consists of too many strings then the system voltage should be increased.

\subsubsection{Panel design}

From the figure, the loss of the system calculated as $40 \%$. Only $60 \%$ of the energy from the solar array is remaining for the battery charging.

From the survey, we know the energy requirement of the system is known.

Hence, energy requirement $=19040 \mathrm{Wh}$

Energy Required in $\mathrm{Ah}=\frac{\text { Totalenergyrequirementofthesystem }}{\text { systemVoltage }}$

Energy from the single Solar Panel $=\frac{I m p \times \text { PeakSun }}{1.4}$

No. of Parallel Strings Required $=\frac{\text { EnergyRequiredinAh }}{\text { EnergyfromthesingleSolarPanel }}$

No. of Panel Required $=$ No. of ParallelStringsRequires $\times 2$ (for 24 Vsystem $)$

Factor 1.4 means $40 \%$ is lost while reaching to the load hence, $40 \%$ loss is compensated by using the extra solar panel. So that the energy output per day is always the required energy for the system.

If ordinary PWM charge controller is used instead of MPPT charge controller, then there occurs extra loss in the system. And, that loss must be compensated by over sizing the panel.

\subsubsection{Charge controller}

Charge controller is a vital component in the ISPS. It not only saves the Battery from over charging or over discharging, it has a vital role in making the system sustainable. Previously, high voltage and low voltage cut off charge controller is used but now a day's PWM charge controller is basically used in most of the system. But for the system to be sustainable MPPT charge controller is to be used.

Maximum Input Current $=\frac{\text { Isc } \times \text { No.of Parallelstringsof Panel }}{0.9}$

Maximum Output Current $=\frac{\text { TotalPower }}{\text { SystemVoltage }}$

Factor 0.9 is that the charge controller so selected is $90 \%$ efficient and is MPPT type.

The size of the charge Controller is selected according to the value of Maximum input or Output Current. Whichever is greater, that value is selected?

\subsubsection{Battery sizing}

First of all, days of autonomy of the system has to be defined. System Voltage, DOD and the efficiency of the Battery and the efficiency of the inverter should be known at this stage.

$$
\text { Battery Capacity }(\mathrm{Ah})=\frac{\text { EnergyRequiredinAh } \times \text { Daysofautonomy }}{\text { Batteryefficiency } \times \text { inverterefficiency } \times D O D}
$$

Battery should be $2 \mathrm{~V}$ high amperage type lead acid battery. For high altitude like Humla where acid is not possible to carry VLRA type should be used. 
Battery should be Deep Cycle high efficiency and high amperage 2V battery type. Hence, for 24 Volt system 12 batteries are connected in a string to make the string 24 Volt.

\subsubsection{Inverter}

Inverter must be high efficiency solar inverter. Ordinary Inverter having low efficiency should not be used. Inverter sizing is as follows. Inverter capacity is in VA.

$$
\text { Hence, } \quad \text { Inverter Capacity }(\mathrm{VA})=\frac{\text { TotalPower }}{\text { Efficienct } \times \text { Powerfactor }}
$$

For designing the system we have to counter the surge current of the equipment. Hence, for safe operation of the inverter the inverter must have either inbuilt surge protector or the Inverter should be oversized.

\subsubsection{Cable and wiring}

Different Cable size is used in different part of the Solar PV system. NS or International standard wire is used in ISPS. Cable of different cross sectional area is selected in different sections of the system like different size of cables are used for Panel wiring, from junction box to Charge controller, Charge Controller to Battery, Battery to Inverter, Battery wiring, inverter to load.There are three factors that dictate the selection of wire size, they are:

a. System Voltage

b. Current flowing in the system

c. Distance between the solar array and the charge controller

Hence, cable sizing is done as: System Voltage $=\mathrm{X}$ volt

Allowable Voltage drop $=3 \%$ of system Volt

$$
=0.03 \times \mathrm{X} \text { volt }
$$

From ohms law,

$\mathrm{V}=\mathrm{R} \times \mathrm{I}$

So, $\Delta \mathrm{V}=\Delta \mathrm{R} \times \mathrm{I}$

We know,

$$
R=\frac{\mathrm{e} \times \mathrm{l}}{A}=\frac{\mathrm{e} \times \mathrm{l}}{A} \quad \text { Or, } \frac{\Delta V}{\mathrm{I}}=\frac{\mathrm{e} \times \mathrm{l}}{A} \quad \text { Or, } \mathrm{A}=\frac{\mathrm{e} \times \mathrm{l} \times \mathrm{I}}{\Delta V} \quad \text { Or, } \mathrm{A}=\frac{\mathrm{e} \times \mathrm{l} \times \mathrm{I}}{\Delta V} \times 1000000 \mathrm{~mm}^{2}
$$

Where,

$\mathrm{Q}=$ resistivity of the cable $=1.7 \times 10^{\wedge} 8$ ohm-meter for copper cable

$\Delta \mathrm{V}=$ allowable voltage drop

$\Delta \mathrm{R}=$ change in resistance due to voltage drop

$\mathrm{L}=$ distance between the panel and the charge controller

$1=2 \times \mathrm{L}$ (Electrical length is twice the physical length)

$I=$ Current flowing through the cable

But, the proposed system of design uses the technology like software to check the calculated value of cable size. Hence cable size is calculated by following links:

http://www.solar-wind.co.uk/cable-sizing-DC-cables.html 


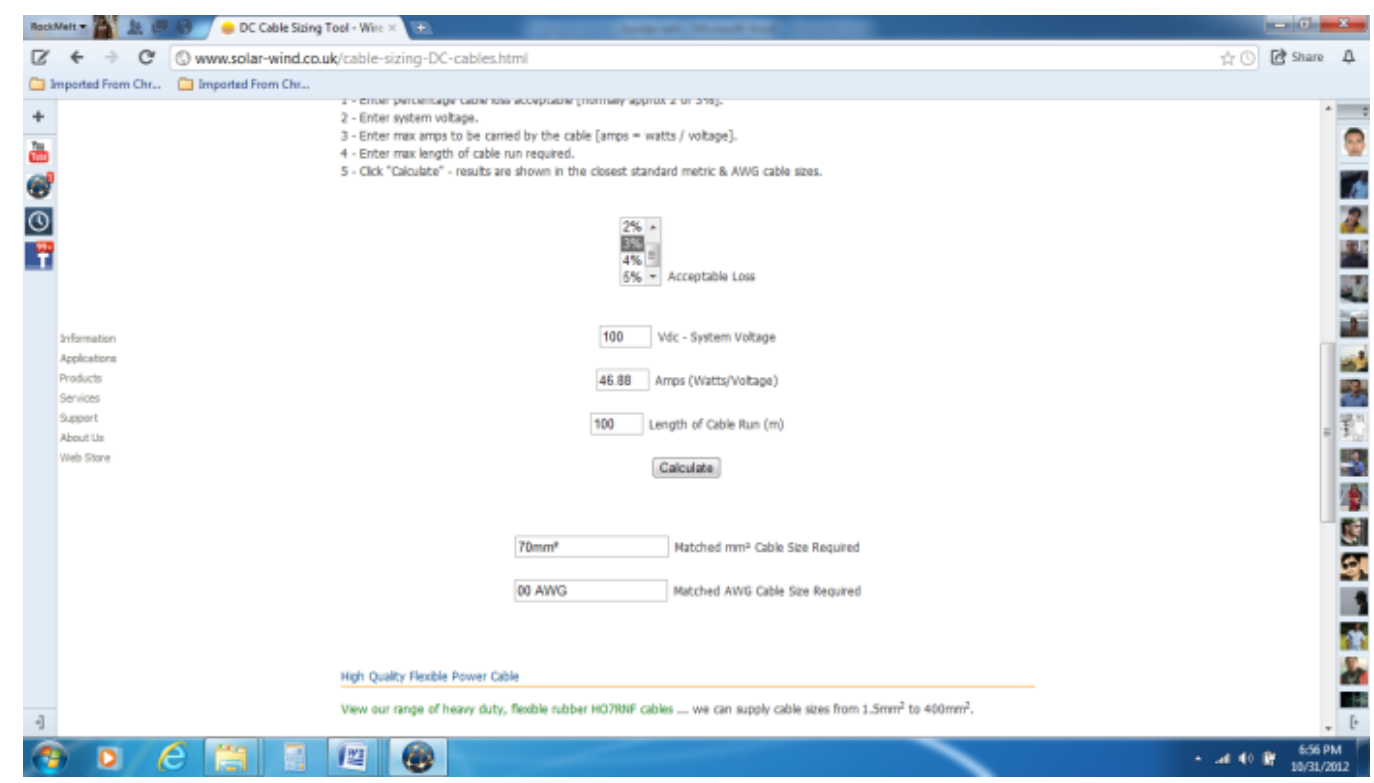

Fig4 Determination of the cable size through the software

\subsubsection{MCB}

For the safe and the sustainability of the system, MCB is used in between Batteries and the inverter. When unknowingly high wattage equipment is connected to the system then the MCB goes down and the system will be safe. Hence, MCB is also important components of ISPS.

\subsubsection{Grounding and protection}

Earthing is done in both input and the output side. For the possibility of high surge, surge protector is used at the input side and for the output side MOV is used. A lightning arrestor is also used to avoid from the extreme earth potential due to lightning strike.

\section{Conclusions and Findings}

Renewable energy has its importance only when it is sustainable. So, an attempt has been made to study the sustainability of the ISPS installed under the AEPC subsidy programme. This study reveals that most of the system is not working after couple of year of installation. A random sample had been taken to study the sustainability of the system. Beside that the PV technologies have some consideration for the sustainability factors to be consider are as follows;

- There is at least $40 \%$ loss in the normal system, which can be minimized by over sizing the system appropriately hence the charging current will not decrease due to the loss in the system.

- Despite the appropriate sizing of the charge controller, MPPT charge controller maintains the power of the panel in state of ordinary PWM charge controller

- While sizing the battery, the losses it may account must be considered and its proper adjustment is also necessary for the sustainability of the system. Battery sizing is an easy task but appropriate sizing is indeed a difficult one. Battery efficiency and the inverter efficiency is an important parameter that should be compensated by the over sizing of the battery.

- $\quad$ Besides sizing of the Inverter, efficiency of inverter is very important for the sustainability aspect of the system. When we put the ordinary inverter in the Solar PV technology, then its efficiency has a range of 60 to $65 \%$ which means $35-40 \%$ loss in the system. Therefore, in Solar PV technology high efficient Solar inverter should be used which is of around $90 \%$ 
efficient. Inverter should sustain the surge current of the equipment. Either we oversize the inverter or we can use the Surge Protector in the system.

- $\quad$ Standard wire should be used. Avoid using 3/22 and 7/22 wire. Wire size is selected on the basis of the current carrying capacity.

- $\quad$ Earthing must be done in the AC system or in large system including the ISPS. Copper cable, copper sheet, salt and coal are used for earthing

\section{References}

1. Borenstein Severin, "The Market Value and Cost of Solar Photovoltaic Electricity Production”, M.Sc. Thesis, Berkeley University, January 2008.

2. Tsai Henry, Business and Financial Analyst, NC Solar Center, North Carolina State University, "Overcoming the Obstacles of Achieving 1 Million Solar Roofs -A New Perspective of Solar Financial Modeling"

3. Linden David, ed., Thomas B. Reddy, ed., "Handbook of Batteries” McGraw Hill Publishing, New York, New York 2002

4. Solar Energy International (Author), "Photovoltaics: Design and Installation Manual."

5. "Selection and Sizing of Batteries for UPS Backup", Ametek Solid State Controls. Columbus, Ohio 43085

6. "Energy Sector Synopsis Report”, Nepal, July 2010.

7. Shrestha J.N, Ph.D. "Application of Building Integrated Photovoltaic Electric System: Its Contribution In Reduction Of Load Shedding Hours In Nepal”

8. Sharma Dinesh Kumar, "Training Manual for Engineers on Solar PV System”, AEPC, ESAP, September 2009.

9. Shrestha J.N., "Photovoltaic Technology - Course Manual, Institute of Engineering", Tribhuvan University, 1999.

10. Linden David, ed., Thomas B. Reddy, ed., "Handbook of Batteries” McGraw Hill Publishing, New York, New York 2002

11. "Status of Solar Photovoltaic sector in Nepal”, December 2009.

12. WECS (Water and Energy Commission Secretarist), 1996

13. MoEST (Ministry of Enviroment Science and Technology). 